\title{
Threshold Cycle
}

National Cancer Institute

\section{Source}

National Cancer Institute. Threshold Cycle. NCI Thesaurus. Code C161328.

The number of signal amplification cycles at which the signal reaches an intensity above the background signal. 